http://jmscr.igmpublication.org/home/ ISSN (e)-2347-176x ISSN (p) 2455-0450 crossref DOI: https://dx.doi.org/10.18535/jmscr/v7i11.178

Journal Of Medical Science And Clinical Research

\title{
A study of pedicle screw fixation combined with an intermediate screw at the fracture level for treatment of thoracolumbar burst fractures without Neurological injury
}

\author{
Authors \\ Dr Ravi Chandra Yadav Madas ${ }^{1^{*}}$, Dr Ameet Hanmant Kulkarni ${ }^{2}$ \\ ${ }^{1}$ Assistant Professor, Department of Orthopedics, Prathima Institute of Medical Sciences, Nagnoor, Karimnagar \\ ${ }^{2}$ Consultant Spinal Surgeon, Apollo Specialty Hospitals, Bengaluru \\ *Corresponding Author \\ Dr Ravi Chandra Yadav Madas \\ Flat No-203, Rithika Residency, Om Sai Colony, Opp Alwal Rythu Bazar, Secunderabad- 500010, Telangana state, \\ India
}

\begin{abstract}
The main aim of the management of thoracolumbar fractures is the stabilization of fractured vertebrae which in turn promotes healing of the fractured vertebrae. The pedicle screw placed at the level of fracture is called an intermediate screw; it has been shown to improve the clinical results in managing thoracolumbar fractures.

Methods: This prospective cross-sectional study was done in the Department of Orthopedics, Prathima Institute of Medical Sciences, Naganoor, Karimnagar. The inclusion criteria were all thoracolumbar fractures without neurological deficits, involving a fracture of the thoracolumbar spine. Exclusion criteria were Patients not under the ambit of inclusion criteria, those with medical conditions who could not undergo surgery, those not willing to participate in the study. The patients were subjected to radiological examination by X-rays, AP and lateral view. MRI/CT scan was done to determine the instability of the spine. The patients were then subjected to pre-surgical laboratory investigations which included complete hemogram, BT \& CT, FBS, LFT, and KFT. Pedicle screw placement was done as per the standard operating procedure. Postoperative antibiotics were given Thoracolumbar orthosis was used from the $4^{\text {th }}$ postoperative day. Postoperative follow up was done up to 1 year.

Results: Out of the total $n=25$ patients $n=17(68 \%)$ were male and $n=8(32 \%)$ were females. The most common age group was 31 - 35 having $n=8(32 \%)$ of patients. The most commonly involved level of fracture was T12 in $40 \%$ of cases followed by L1 in 36\% of cases. As per AO classification, the A1 was $36 \%$ followed by A2 $32 \%$ and A3 24\%. The mean preoperative VAS score was 8.5 and at the last follow up the mean VAS scores were 1.5. The most commonly encountered complication was wound infection in $n=2(8 \%)$ of the patients followed by screw misplacement in $n=1(4 \%)$.

Conclusion: The results of the present study shows that the intermediate pedicle screw placement has several advantages like better correction of kyphotic angle, ability to maintain the height of injured vertebrae and reduce the correction loss at follow up. The overall stress distribution pattern is favorable in the intermediate screw placement technique. Hence this technique may be considered for the treatment of unstable thoracolumbar burst fractures.

Keywords: Pedicle Screw Fixation, Intermediate Screw, Thoracolumbar Burst Fractures.
\end{abstract}




\section{Introduction}

Thoracolumbar compression fractures are one of the common fractures in the spine caused by the failure of the anterior and middle columns of the vertebral body due to flexion forces ${ }^{[1]}$. A greater portion of thoracolumbar fractures occurs at the level of T11 to L2 which are generally weaker areas against external stress force ${ }^{[2]}$. The thoracolumbar fractures are caused due to high energy impacts such as motor vehicle accidents and fall from height ${ }^{[3]}$. Surgical treatment of thoracolumbar fractures can decrease the rate of complications associated with prolonged immobility ${ }^{[4]}$. Pedicle screw systems, which were first introduced by Boucher, have been widely used in the instrumentation of the lumbar spine ${ }^{[5]}$. Posterior short-segment pedicle screw fixation which is done one level above and one level below the fracture level is the most widely used method for thoracolumbar fractures. The advantage includes providing immediate spinal stability, improved correction of kyphotic deformities, early mobilization and indirect decompression of spinal canal. Many studies have reported that short-segment pedicle screw instrumentation may not be adequate to achieve and maintain the reduction of thoracolumbar fractures and is associated with unacceptable failure rate $e^{[6-9]}$. The biomechanical studies of thoracolumbar fractures by pedicle screw fixation at fractured vertebrae since first reported in 1994 have shown that pedicle screw fixation combined with screws at the fractured improves the spinal stability ${ }^{[10-12]}$. It also decreases the level of stress by pedicle screws in the upper and lowers normal vertebrae. JC Dick et al; ${ }^{[13]}$ have shown that that the addition of intermediate screws at the fractured vertebrae can obtain stronger fixation and decrease the reduction of vertebral height as compared to the conventional pedicle screw fixation. Anekstein $\mathrm{Y}$ et al; ${ }^{[14]}$ Baaj AA et al; ${ }^{[11]}$ and Norton RP et al; ${ }^{[12]}$ have shown that pedicle screw at the fracture levels did improve the stability of pedicle screw fixation and decrease the stress on each pedicle screw. However, Hakalo et al; ${ }^{[15]}$ have found that pedicle screw insertion into fractured vertebrae did not effectively increase the spinal axial bearing capacity and stability. It also did not reduce the post-operative correction loss and the failure rate of internal fixation. With this background, we in the present study tried to evaluate the clinical outcome of pedicle screw fixation combined with an intermediate screw at the fracture level for the treatment of thoracolumbar burst fractures.

\section{Material and Methods}

This prospective cross-sectional study was done in the Department of Orthopedics, Prathima Institute of Medical Sciences, Naganoor, Karimnagar. Institutional Ethical committee permission was obtained for the study. Written consent was obtained from all the participants of the study. The inclusion criteria were all thoracolumbar fractures T10-L3 without neurological deficits, involving a fracture of the thoracolumbar spine. Exclusion criteria were Patients not under the ambit of inclusion criteria, those with medical conditions who could not undergo surgery, those not willing to participate in the study. A complete record of the patient which included a detailed history, complete clinical examination to neurological deficits and spinal deformity was done. The patients were subjected to radiological examination by X-rays, both AP and lateral view. $\mathrm{MRI} / \mathrm{CT}$ scan was done to determine the instability of the spine. The patients were then subjected to pre-surgical laboratory investigations which included complete hemogram, BT \& CT, FBS, LFT, and KFT. The patients were operated under General Anesthesia, the position of the patient was prone to the spinal operating table which created lordosis. A posterior midline incision was made over the involved spinal unit extending one level above and one level below. The dissection was done until the tip of the transverse process. The pedicle entrance point was demarcated by the line that connects the middle transverse processes and the lateral edge of the facet. For the thoracic spine, the entrance point is 
in line with the middle of the transverse process about $2 \mathrm{~mm}$ below the inferior edge of the facet. The cortical bone is removed and the pilot hole was made with a trocar with stopper. The depth of the pedicle is confirmed with the probe by the marking on it and confirming position by passing it to $80 \%$ of its depth. The pedicle screws were then inserted into both the above and below vertebrae to the fracture level. Both mono and polyaxial screws were used. Under fluoroscopic guidance, the screws were also inserted into the pedicles of the fractures vertebrae (Intermediate screws). The intermediate screws were inserted in both the pedicles of the fractured vertebrae however if pedicle was also fractured no screw was inserted into the pedicle. The length of the intermediate screws was generally kept short so that it just enters the vertebral body after crossing the pedicle. The contouring of the rod depended on the site of the fracture. A straight or a slightly lordotic rod was chosen for fractures from T11L1, and a rod contoured to lordosis was chosen for lumbar fractures. The rod was introduced to the screw heads from distal to proximal and the distal screw head is tightened first. The proximal and intermediate screw heads were kept loose. The rod was also inserted into the proximal screw heads without tightening. With the help of a rod holder and a distractor, the proximal screws are distracted along the rod. This was done on both sides simultaneously. The locking heads of the proximal and intermediate screws were tightened to secure the distraction achieved. Fusion was performed in highly unstable fractures like A2, B2, and B3. Non-fusion fixation is performed in A3, A4, and B1 type of injuries. Before wound closure, intra-operative imaging was performed to check the adequacy of reduction, position, and length of screws and the overall coronal and sagittal spinal alignment. The wound was closed in layers with a drain in place. The clean dressing was applied. Postoperative antibiotics were given IV which included third-generation cephalosporin and aminoglycosides for five days. The oral antibiotics were continued till the sutures were removed on the $10^{\text {th }}$ postoperative day. Physiotherapy exercises were started from the next postoperative day. Postoperative follow was done up to 1 year.

\section{Results}

Out of the total $\mathrm{n}=25$ patients, $\mathrm{n}=17(68 \%)$ were male and $\mathrm{n}=8(32 \%)$ were females. The most common age group was $31-35$ having $n=8(32 \%)$ of all patients followed by $n=7(28 \%)$ in the age group 26 - 30 years. The age group 21-35 contributed to $n=17(68 \%)$ of the total patients in the study given in table 1 .

Table 1: showing the demographic profile of the cases in the study

\begin{tabular}{|l|c|c|c|c|}
\hline Age Group & Male & Female & Total & Percentage \\
\hline $\mathbf{2 1}-\mathbf{2 5}$ & 02 & 00 & 02 & 08 \\
\hline $\mathbf{2 6}-\mathbf{3 0}$ & 06 & 01 & 07 & 28 \\
\hline $\mathbf{3 1}-\mathbf{3 5}$ & 04 & 04 & 08 & 32 \\
\hline $\mathbf{3 6}-\mathbf{4 0}$ & 02 & 02 & 04 & 16 \\
\hline $\mathbf{4 1}-\mathbf{4 5}$ & 02 & 01 & 03 & 12 \\
\hline $\mathbf{4 6}-\mathbf{5 0}$ & 01 & 00 & 01 & 04 \\
\hline Total & 17 & 08 & 25 & 100 \\
\hline
\end{tabular}

The most commonly involved level of fracture was T12 in $40 \%$ of cases followed by L1 in $36 \%$ of cases. The total numbers of cases at T12-L1 were $76 \%$ of cases. The other distributions of cases from T8 to L3 are given in table 2.

Table 2: Showing the location of fractures in the cases of study

\begin{tabular}{|l|c|c|}
\hline Fracture level & Frequency & Percentage \\
\hline T8 & 01 & 04 \\
\hline T11 & 02 & 08 \\
\hline T12 & 10 & 40 \\
\hline L1 & 09 & 36 \\
\hline L2 & 02 & 08 \\
\hline L3 & 01 & 04 \\
\hline Total & 25 & 100 \\
\hline
\end{tabular}

The thoracolumbar fractures in the study were classified as per the AO classification system [reference 1 below]. The A1 was $36 \%$ followed by A2 $32 \%$ and A3 24\%. The total number of fractures in A group was 92\%. Only $8 \%$ of fractures were belonging to B category in which $\mathrm{B} 1$ and B2 were $4 \%$ each respectively. No cases of $\mathrm{C} 1$ or $\mathrm{C} 2$ were noted in our study shown in 
table 3 . In the study $n=17(68 \%)$ cases were due to fall from height and $n=8(32 \%)$ were due to Road traffic accidents chart 1 .

Table 3: showing the AO classification ${ }^{[16]}$ of fractures in patients of the study

\begin{tabular}{|l|c|c|}
\hline AO Fracture classification & Frequency & Percentage \\
\hline A1 & 09 & 36 \\
\hline A2 & 08 & 32 \\
\hline A3 & 06 & 24 \\
\hline B1 & 01 & 04 \\
\hline B2 & 01 & 04 \\
\hline C1 & 00 & 00 \\
\hline C2 & 00 & 00 \\
\hline
\end{tabular}

Chart 1: Showing the cause of fractures in cases of the study

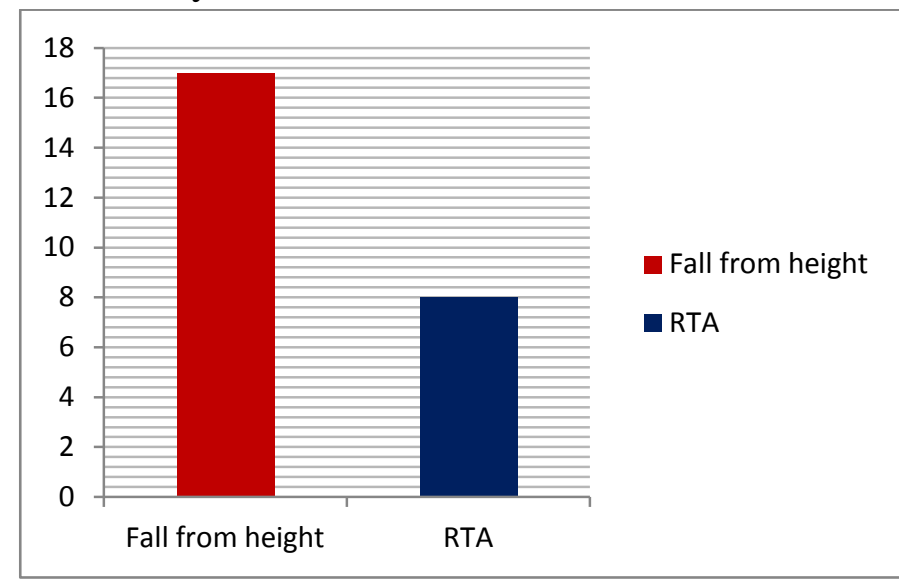

Table 4: Showing the mean operative indices of the patients in the study

\begin{tabular}{|l|c|c|}
\hline Operative indices & Mean & $\begin{array}{l}\text { Standard } \\
\text { deviation }\end{array}$ \\
\hline $\begin{array}{l}\text { Mean operative time } \\
\text { (min) }\end{array}$ & 185.0 & 42.5 \\
\hline $\begin{array}{l}\text { Intra-operative blood } \\
\text { loss (ml) }\end{array}$ & 350.5 & 100.2 \\
\hline $\begin{array}{l}\text { Postoperative drainage } \\
\text { volume (ml) }\end{array}$ & 120.5 & 80.6 \\
\hline $\begin{array}{l}\text { Mean duration of } \\
\text { hospital stay (days) }\end{array}$ & 25.5 & 5.5 \\
\hline
\end{tabular}

VAS scale for pain assessment was used with '0' no pain to ' 10 ' severe pain. The mean preoperative VAS score was 8.5. On the $3^{\text {rd }}$ postoperative day the mean VAS scores were 4.5 and the VAS scales gradually reduced on discharge day the VAS scores were 2.1 and the last follow up at 1 year the mean VAS Scores were 1.5 shown in table 5 .
Table 5: Visual Analogue Scales [VAS] score of the cases in the study

\begin{tabular}{|l|c|c|}
\hline $\begin{array}{l}\text { VAS at a different } \\
\text { interval }\end{array}$ & $\begin{array}{c}\text { Mean VAS } \\
\text { score }\end{array}$ & $\begin{array}{c}\text { Standard } \\
\text { deviation }\end{array}$ \\
\hline Pre-operative & 8.5 & 1.6 \\
\hline $3^{\text {rd }}$ postoperative day & 4.5 & 1.5 \\
\hline $10^{\text {th }}$ postoperative day & 3.5 & 1.4 \\
\hline On discharge & 2.1 & 0.9 \\
\hline 6 months postoperative & 1.9 & 0.6 \\
\hline 1-year postoperative & 1.5 & 0.5 \\
\hline
\end{tabular}

The mean preoperative regional angle was $15.2^{\circ}$, at three months post-operation the angle was $4.9^{\circ}$ and after 1 year of operation was $4.40^{\circ}$. The mean anterior wedge angle was $19.05^{\circ}$ before surgery and it was reduced to $5.3^{\circ}$ after the operation. The mean vertebral height which was $15.9 \mathrm{~mm}$ at the pre-operation was increased to $23.9 \mathrm{~mm}$ one year of operation given in table 6 . The frequency of complication was recorded in the study the most commonly encountered complication was wound infection in $n=2(8 \%)$ of the patients followed by incorrect screw positioning in $n=1(4 \%)$. No other complication was recorded in the cases of study.

Table 6: The Regional angle, Anterior Wedge angle and vertebral height of cases in the study

\begin{tabular}{|l|c|c|c|}
\hline Variable & $\begin{array}{c}\text { Mean Regional } \\
\text { angle (degree) }\end{array}$ & $\begin{array}{c}\text { Mean Anterior } \\
\text { wedge angle } \\
\text { (degree) }\end{array}$ & $\begin{array}{c}\text { Mean } \\
\text { Vertebral } \\
\text { height in } \\
(\mathbf{m m})\end{array}$ \\
\hline Pre Operative & 15.2 & 19.05 & 15.9 \\
\hline $\begin{array}{l}\mathbf{3} \text { months } \\
\text { Postoperative }\end{array}$ & 4.9 & 5.1 & 23.2 \\
\hline $\begin{array}{l}\text { 6 months } \\
\text { Postoperative }\end{array}$ & 4.66 & 5.5 & 22.9 \\
\hline 1 year & 4.40 & 5.3 & 22.3 \\
\hline
\end{tabular}

Table 7: showing the rate of complication in the study

\begin{tabular}{|l|c|c|}
\hline Complications & Frequency & $\begin{array}{c}\text { Percentage } \\
\text { (total n=25) }\end{array}$ \\
\hline Wound infection & 02 & 08 \\
\hline $\begin{array}{l}\text { Incorrect screw } \\
\text { positioning }\end{array}$ & 01 & 04 \\
\hline Screw fracture & 00 & 00 \\
\hline $\begin{array}{l}\text { Neurological } \\
\text { symptoms }\end{array}$ & 00 & 00 \\
\hline Total & 03 & 12 \\
\hline
\end{tabular}

\section{Discussion}

The surgical management of thoracolumbar burst fractures varies depending on several factors that 
include fracture morphology, neurological status, and surgeon preference. Burst fractures account for $20 \%$ of thoracolumbar fractures and occur due to an axial loading force which fails to support the anterior and middle column ${ }^{[17,18]}$. There are two approaches the anterior and posterior approach for the spine. While anterior surgery is effective to remove retropulsed fragments posterior surgery is now becoming increasingly popular because it is easy as well as allows clearance of spinal canal by ligmentotaxis ${ }^{[19,20]}$. The posterior intermediate screw fixation at the level of fracture can improve and maintain the kyphosis corrections and the biomechanical stability is also increased ${ }^{[21-24]}$. Norton RR et al; ${ }^{[12]}$ have shown that the addition of two screws in the fractured vertebra of an unstable burst fracture resulted in increased stiffness of the implant, and reduce the stress on each pedicle screw compared to the conventional four screw construct. Ji-Wei Tian et al; ${ }^{[25]}$ in their retrospective study of 62 patients comparing the results of posterior short-segmental fixation combined with intermediate screws or conventional 4-screw intersegmental fixation found that pedicle screw fixation of fractured vertebra did not achieve better correction of a segmental kyphotic angle compared to conventional intersegmental fixation. However, they have reported that 6 screw fixation of fractured vertebra allowed patients to ambulate approximately 10 days earlier than those undergone conventional screw placements. In the present study, the mean preoperative VAS score was 8.5. On the $3^{\text {rd }}$ postoperative day, the mean VAS scores were 4.5 and the VAS scales were gradually reduced on discharge day the VAS scores were 2.1 and the last follow up at 1 year the mean VAS scores were 1.5 . Wang et $\mathrm{al}^{[10]}$ comparing the conventional to combined screw fixation found the mean VAS score was 1.6. Yin et al; ${ }^{[26]}$ also in a similar study found the mean VAS score was 2.2 in close agreement with the results of the present study. In the present study, the mean vertebral height was $22.3 \mathrm{~mm}$ at the end of one year of treatment. The mean regional angle was $15.2^{\circ}$ pre-operative was reduced to $4.4^{\circ}$ at the end of one year of treatment. Nasser MG et al; ${ }^{[27]}$ evaluating the conventional screw placement patients noted that kyphotic angle at pre-operative state was $23.6^{\circ}$ and was reduced to $7^{\circ}$ postoperatively and $11.5^{\circ}$ at latest follow-up. Razak M. et al; ${ }^{[28]}$ noted that the average kyphotic angle was $20^{\circ}$ preoperatively, $7^{\circ}$ postoperatively and $9^{\circ}$ at the latest follow up. The overall rate of complication in the study was $12 \%$. The complication rate in published literature has shown inconsistent rates. However, in the present study, there were only two cases of wound infection which were managed with antibiotics. There were no instances of hardware failure. This is explained by the fact that the combined screw at fractured vertebrae could significantly improve stress distribution between the screws. The load to screw is reduced and hence enhances the stability of fixation ${ }^{[29,30]}$.

\section{Conclusion}

The results of the present study show that the intermediate pedicle screw placement has several advantages like better correction of kyphotic angle, ability to maintain the height of injured vertebrae and reduce the correction loss at follow up. The overall stress distribution pattern is favorable in the intermediate screw placement technique. Hence this technique may be considered for the treatment of unstable thoracolumbar burst fractures.

\section{Conflict of interest: None \\ Source of support: Nil \\ Ethical Permission: Obtained}

\section{Reference}

1. Denis F, Armstrong GW, Searls K, Matta 1. Acute thoracolumbar burst fractures in the absence of neurologic deficit. A comparison between operative and nonoperative treatment. Clin Orthop Relat Res 1984: 142-49. 
2. Gertzbein SD. Scoliosis Research society Multicenter spine fracture study. Spine (Phila Pa 1976) 1992; 17:528-40.

3. Katsuura Y, Osborn JM, Cason GW. The epidemiology of thoracolumbar trauma: A meta analysis. J Orthop 2016;13:383-38.

4. Butt MF, Farooq M, Mir B, Dhar AS, Hussain A, Mumtaz M. Management of unstable thoracolumbar spinal injuries by posterior short segment spinal fixation. Int Orthop 2007; 31: 259-64.

5. Hicks JM, Singla A, Shen FH, Arlet V. Complications of pedicle screw fixation in scoliosis surgery: A systematic review. Spine (Phila Pa 1976) 2010; 35: E465E470.

6. Wood KB, Bohn D, Mehbod A. Anterior versus posterior treatment of stable thoracolumbar burst fractures without neurologic deficit: a prospective randomized study. J Spinal Disrod Tech 2025; 18(supp 1):S15-23.

7. McLain RF, Sparling E, Benson Dr. Early failure of short-segment pedicle instrumentation for thoracolumbar fractures. A preliminary report.J Bone Joint Surg Am 1993;75:162-67.

8. Scholl BM, Theiss SM, Krikpatrick JS. Short segment fixation of thoracolumbar burst fractures. Orthopedics 2006; 29:70308.

9. Bolesta MJ, Caron T, Chinthakunta ST et al; pedicle screw instrumentation of thoracolumbar burst fractures: Biomechanical evaluation of screw configuration with pedicle screws at the level of the fracture. Int $\mathbf{J}$ Spine Surg 2012;6:200-05.

10. Wang H, Li C, Liu T et al; Biomechanical efficacy of monoaxial or poly axial pedicle screw and additional screw insertion at the level of fracture in lumbar burst fracture: an experimental study. Indian J Orthop 2012; 46:395-01.
11. Baaj AA, Reyes PM, Yaqoobi AS et al; Biomechanical advantage of index level pedicle scres in unstable thoracolumbar junction fractures. J Neurosurg Spine 2011; 14:192-97.

12. Norton RP, Milne EL, Kaimrajh DN et al; biomechanical analysis of four versus sixscrew constructs for short-segment pedicle screw and rod instrumentation of unstable thoracolumbar fractures. Spine J 2014; 14:174-39.

13. Dick JC, Jones MP, Zdeblick TA et al. A biomechanical comparison evaluating the use of intermediate screws and crosslinkage in lumbar pedicle fixation. J Spinal Disord 1994; 402-27.

14. Anekstein Y, Brosch T, Mirovsky Y. Intermediate screw in short segment pedicular fixation for thoracic and lumbar fractures: a biomechanical Study. J Spinal Disord Tech 2007;20:72-77.

15. Hakalo J, Wronski J. Complications of a transpedicular stabilization of thoracolumbar burst fractures. Neurologia i neruochirurgia polska 2006; 40:134-39.

16. Magerl F, Aebi M, Gertzbein SD, Harms J, Nazarian S. A comprehensive classification of thoracic and lumbar injuries. Eur Spine J. 1994; 3(4):184-01.

17. Benson DR, Burkus JK, Montesano PX, Sutherland TB, McLain RF. Unstable thoracolumbar and lumbar burst fractures treated with the AO fixateur interne. J Spinal Disord. 1992;5: 335-43.

18. Crawford NR, Dickman CA. Construction of local vertebral coordinate systems using a digitizing probe. Tech Note Spine. 1997; 22:559-63.

19. Limb D, Shaw DL, Dickson RA. Neurological injury in thoracolumbar burstfractures. J Bone Joint Surg Br. 1995; 77:774-77.

20. Kaneda K, Taneichi H, Abumi K, Hashimoto T, Satoh S, Fujiya M. Anterior decompression and stabilization with the 
Kaneda device for thoracolumbar burst fractures associated with neurological deficits. J Bone Joint Surg Am. 1997;79:69-83.

21. Sun C, Guan G, Liu X, Zhang H, Wang B. Comparison of short-segment pedicle fixation with versus without inclusion of the fracture level in the treatment of mild thoracolumbar burst fractures. Int J Surg. 2016;36 :Pt A:352-57.

22. Kose $\mathrm{KC}$, Inanmaz ME, Isik C, Basar H, Caliskan I, Bal E. Short segment pedicle screw instrumentation with an index level screw and cantilevered hyperlordotic reduction in the treatment of type-A fractures of the thoracolumbar spine. Bone Joint J. 2014;96-B(4):541-47.

23. Dobran M, Nasi D, Brunozzi D, Di Somma L, Gladi M, Iacoangeli M, et al. Treatment of unstable thoracolumbar junction fractures: short-segment pedicle fixation with inclusion of the fracture level versus long-segment instrumentation. Acta Neurochir (Wien). 2016; 158(10):188389.

24. Ozdemir B, Kanat A, Erturk C, Batcik OE, Balik MS, Yazar U, et al. Restoration of anterior vertebral height by short-segment pedicle screw fixation with screwing of fractured vertebra for the treatment of unstable thoracolumbar fractures. World Neurosurg. 2017; 99:409-17.

25. Ji-Wei Tian, Lei Wang, Tian Xia, ChengYi Liu, Qing-Hua Zhao, Shuang-Hai Dong. Posterior Short-segmental Fixation Combined with Intermediate Screws vs Conventional Intersegmental Fixation for Monosegmental Thoracolumbar Fractures. Orthopedics 2011; 34(8):e389-96.
26. Yin F, Sun Z, Yin Q et al. A comparative study on treatment of thoracolumbar fracture with injured vertebra pedicle instrumentation and cross segment pedicle instrumentation. Zhongguo xiu fu chong Jian wai ke zhi 2014; 28:227-32.

27. Nasser R, Yadla S, Maltenfort MG, Harrop JS, Anderson DG, Vaccaro AR, Sharan AD, Ratliff JK. J Neurosurg Spine. 2010 Aug; 13(2):144-57.

28. Razak M, Mahmud MM, S.A. Hyzan MY, Omar A, Short segment posterior instrumentation, reduction and fusion of unstable thoracolumbar burst fractures - a review of 26 cases, Med J Malaysia, 2000, Sep, 55 Suppl, C: 9 - 13.

29. Huang W, Luo T. Efficacy analysis of pedicle screw internal fixation of fractured vertebrae in the treatment of thoracolumbar fractures. Exp Ther Med 2013; 5:678-82.

30. Lehman RA Jr. Lenke LG, Keeler KA et al. Computed tomography evaluation of pedicle screws placed in the pediatric deformed spine over an 8-year period. Spine 2007; 32:2679-84. 